\title{
New Product Development in Traditional Industries: Decision-Making Revised
}

\author{
Jon Mikel Zabala-Iturriagagoitia'
}

\begin{abstract}
This paper investigates whether decisions considered as common in new product development literature are also valid in a region characterized by traditional industries. The research is grounded on innovative companies in the Valencian Region (Spain). Using the statistical tool of factor analysis, we test if the groups of decisions identified by the literature can be confirmed in our empirical sample. Therewith, we aim to link the theoretical and empirical fields in the context of new product development and product innovation management.
\end{abstract}

Keywords: New product development; decision making; innovative firm; traditional industry; valencian region.

\footnotetext{
I Centre for Innovation, Research and Competence in the Learning Economy (CIRCLE), Lund University, P.O. Box II 7, SE-22 I00, Lund (Sweden) Phone: +46 462223362 Fax:+46 46222 4I 6I.E-mail: jon_mikel.zabala@circle.lu.se
} 


\section{Introduction}

Innovation is a complex process covering different dimensions (technological, product, process, organizational, managerial, marketing, etc.). In order to introduce new goods (product or service) in the market, firms develop several activities, labelled as New Product Development (NPD) (Haverila, 20I0).

The success of the NPD process depends, among other factors, on the integrated decision-making ability of the agents intervening in it (Krishnan, 1998). The decisions made during the NPD process have a critical impact both on the final output and the activities constituting the NPD process. Decision-makingactivities constitutea considerable percentage of the time invested in the development of a new good, determining the final product's quality, innovation and costs, as well as the overall efficiency of the firm (Tsinopoulos and McCarthy, 2002). It is acknowledged that the way in which products and services are developed differs across firms and sectors (and also within the same firm over time). However, the decisions made during these development processes remain fairly constant (Hansen, 200I; Krishnan and Ulrich, 200I: 3). In other words, the process remains invariable while the output evolves.

Several scholars have addressed decision-making processes in new product development processes (Garavelli et al., 1999; Kengpol and O'Brien, 200I; McCarthy et al., 2006; Harmancioglu et al., 2007). After a thorough review of the literature, Krishnan and Ulrich (200I) present an extensive list of the most common decisions made in each phase of the NPD process. However, in spite of the relevance of their theoretical contribution, their work has not been empirically proven so far (Garavelli et al., 1999).

In this paper we aim to empirically investigate the applicability of the decision perspective of product development presented by Krishnan and Ulrich in their 200 I paper. The ultimate purpose of this analysis is to test whether the decisions considered as usual in NPD literature are also empirically valid in a territory characterized by its traditional industries. From our point of view, the decisions listed in the literature are mostly addressed to big companies having an international dimension, firms with the ability to influence not only the idea/concept of their product, their design and prototyping, but also the supply chain and the marketing of the product. Besides, these are mostly applicable to R\&D based sectors with high technological complexity, first-mover advantage (e.g. computers and software, car industry) and where radical and incremental innovations are produced. However, not much attention is paid so far to traditional sectors. These traditional industries can be characterized as being imitators, supplier dominated, technology adopters and whose competitiveness is dependent on customer preferences and fashion (Alcaide-Marzal and Tortajada-Esparza, 2007: 37). Consequently, despite innovation is at the core of their competitiveness, this is not produced by the introduction of complex developments or technologies discovered in labs or together with university researchers. Innovation is mostly done by adaptation (Molero and Garcia, 2008) and acquisition of foreign machinery (Fernández de Lucio et al., 2000).

We attempt to check if the approach followed by Krishnan and Ulrich (200I) is generalized enough so as to apply it to an empirical study grounded on innovative companies in the Valencian Region (Spain). This region is a characterized by having a great number of micro-firms (up to 10 employees) (Sheikh et al., 2002) and Small and Medium Size Enterprises (SMEs) (up to 50 employees') (Arosa et al., 20I0) in a diverse set of industrial sectors. Some of these sectors stand out as pioneers in Spain and Europe in traditional areas such as agriculture, tiles, furniture, shoes, textiles and toys.

The remaining of the paper is structured as follows. In section 2 we review the literature regarding NPD, illustrating its major phases and defining its foremost features. A detailed description of the questionnaire design, sample choice and data collection are provided in section 3 . Section 4 presents the main results of our empirical study. First we describe the main characteristics of decision-making processes of Valencian innovative firms in their NPD practices. Second we compare our results with those identified by Krishnan and Ulrich. Finally, the contribution of the study in discussed in section 5, drawing conclusions and indicating directions for further research.

\footnotetext{
1 According to official statistics, SMEs comprises up to 250 employees. However, in the Spanish context, only a $0,1543 \%$ of the companies are listed as being larger than 250 employees (INE, 20I I).
} 


\section{New Product Development and the rele- vance of decision-making processes}

NPD is defined as "the transformation of a market opportunity and a set of assumptions about product technology into a product available for sale" (Büyüközkan and Feyzioglu, 2004: 28). It is an interdisciplinary process that requires the involvement of almost all the functions of a firm, from product design to marketing (Haque et al., 2000). As a result, firms can obtain a good (product or service) which is new-to-the-firm, new-to-the-market (in this case it might be considered as a radical innovation) or a significant upgrade (an improvement of an existing good either in the firm or in the market, i.e. an incremental innovation).

NPD is regarded as an integral part of innovation processes (Büyüközkan and Feyzioglu, 2004). Two clear examples of the mutual dependence between NPD and innovation are the correspondence between terms like 'product creation process' and 'product innovation process' (Buijs, 2008). For Schumpeter (1934), the concept of innovation covers five areas: (i) the introduction of new goods (product innovation), (ii) the introduction of new production methods (process innovation), (iii) the opening of new markets (market innovation), (iv) the use of new sources of supply of raw materials or intermediate inputs (input innovation), and ( $v$ ) the development of a new organizations (organizational innovation) $^{2}$. Similarly, the Oslo Manual defines four types of innovations that encompass a wide range of changes in firms' activities: product innovations, process innovations, organizational innovations and marketing innovations (OECD, 2005). Since this paper is dealing with NPD processes, we will exclusively focus on product innovations.

There have been several attempts to develop conceptual models of the NPD process (Hart and Baker, 1994; Tuominen et al., 1999; Harmancioglu et al., 2007; Schmidt et al., 2009). Cooper (1983, 1988) was one of the first authors that determinedly influenced NPD research, by dividing the NPD process into several sequential stages or phases. Some other contributions include those by Cooper and Kleinschmidt (1987), Mahajan and Wind (1992), Emmanuelides (1993) and Poolton and Barclay (1998) to mention a few.
The NPD process (Figure I) can be structured into distinct stages (Cooper, 1983; Urban and Hauser, 1993) including the idea generation, the development of the concept, the product testing and its commercialization among others. After a comprehensive review of the literature, Buijs (2008: 322) offers a list of 54 activities constituting NPD processes, divided into three groups: pre, core and post NPD activities. Similarly, McCarthy et al. (2006) develop a complex adaptive system that contributes to the theory by extending the linear, recursive, and chaotic approaches to the NPD process.

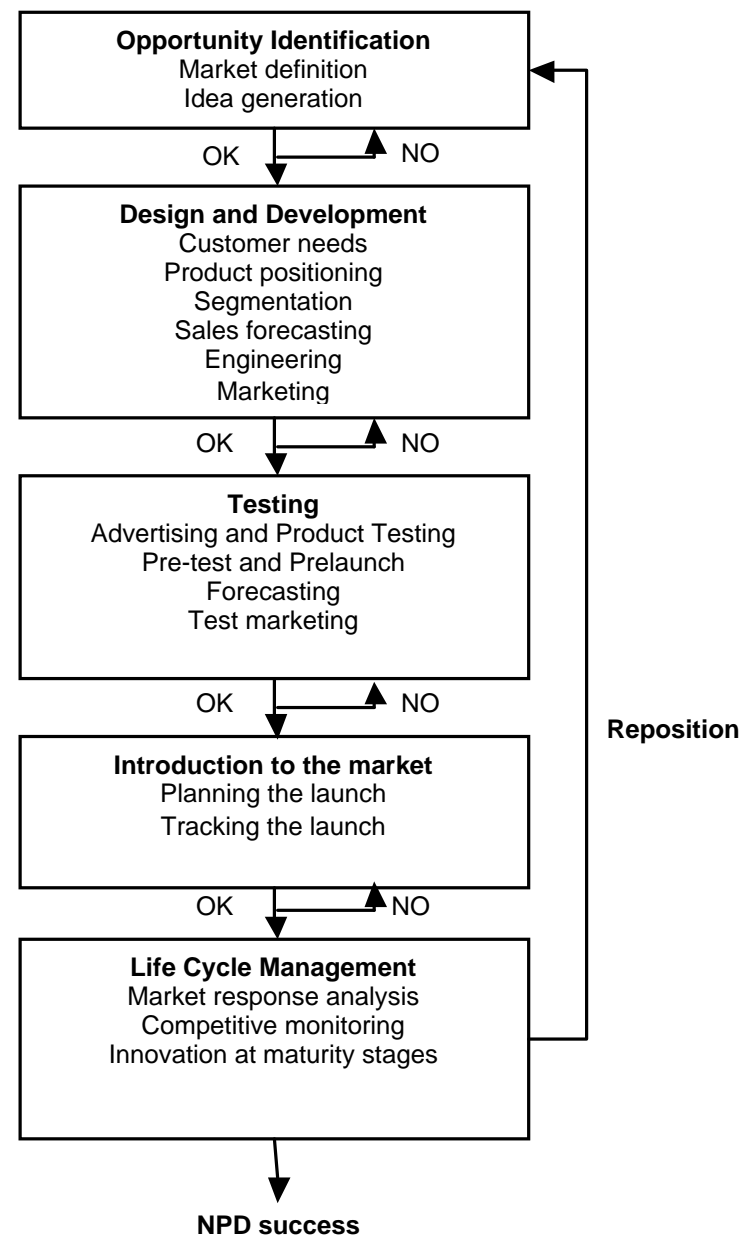

Figure I.- Stages of the NPD process ${ }^{3} /$ Source: Matheson and Matheson (1998)

\footnotetext{
2 More recently Chesbrough (2003) has introduced the concept of open innovation while Moulaert et al. (2007) have contributed with the social innovation approach. We will come back to this in the conclusion section.

${ }^{3}$ Despite this illustration of the NPD process might be considered as a linear approach to innovation, in the literature some other NPD models can be found based upon concurrent engineering (Hart and Baker, 1994).
} 
NPD processes have some particular features. They are intangible and irreversible in nature and the benefits are usually obtained in the long run (Büyüközkan and Feyzioglu, 2004: 3I). From our point of view, the characteristic that might better explain these processes is uncertainty (Emmanuelides, 1993; Guimarães Marujo, 2009). The features of the product, the customer needs, the particularities of the niche market, the commercialization mechanisms, etc. are all undefined dimensions of NPD processes ${ }^{4}$.

Due to the several dimensions of uncertainty, decisionmaking processes constitute one of the key issues within NPD (Kengpol and O'Brien, 200I; Krishnan and Ulrich, 200I). This is one of the goals of this paper, studying the decision-making processes of innovative firms in their NPD processes. According to Srinivas and Shekar (1997: 100) a decision-making process can be defined "as a set of actions and dynamic factors which begin with the identification of a stimulus for action and ends with the specific commitment to action". Due to the complexity and amount of NPD-related decision-making processes, and so as to make them more feasible to managers, it becomes necessary to divide these decisions into structured and manageable elements (Krishnan, 1998). The decisions made during NPD processes can so be divided into two major groups (Srinivas and Shekar, 1997): (i) repetitive decisions, that is, systematic processes that can be represented as algorithms (structured decisionmaking); and (ii) those than require human judgement (unstructured decision-making).

Krishnan and Ulrich (200I), after a thorough review of the literature, identified an extensive list of the most common decisions made in each phase of the NPD process. They grouped these decisions in two main blocks (see Table 2): (i) those made during the development of the NPD process (concept development, supply chain design, product design, performance testing and validation and production ramp-up and launch); and (ii) those concerning the set up of the NPD project (product strategy and planning, product development organization and project management). However, while rigorous at a bibliographical level, this work has not been empirically verified yet to the best of our knowledge. Besides, we believe most of the decisions identified by Krishnan and Ulrich are adequate for manufacturing firms in medium and high-tech industries. But, is their list of decisions also appropriate in a context of micro-firms and SMEs? Are they also valid in an environment where innovation is done by adaptation? Do they also apply to firms in traditional industries? By focusing in a region with low R\&D orientation, with industries positioned in low-technology sectors, family oriented micro and SMEs, and where innovation is mostly done by adaptation, we aim to examine the degree of universality of the decisions they listed. Therewith, we aim to link the theoretical and empirical fields in the context of NPD and product innovation management.

\section{Data and Methodology}

This section is divided into three main parts. The first deals with the target population for the study. The second encompasses the design of the questionnaire circulated to the firms in the population. Finally, the third subsection addresses the main characteristics of the firms in the sample and the way the data were collected, combined and analyzed.

\section{I. Target population: innovative firms in the Valencian Region}

The study focuses on innovative companies in the Valencian Region (Spain). This is one of the peripheral Spanish regions, located on the Mediterranean coast, covering an area of about 23.000 square kilometres, $4,6 \%$ of the country. In 2010 its population was above 5 million inhabitants, $10,9 \%$ of the total Spanish population (47.02I.03I inhabitants) (INE, 20II). In 2009 its regional GDP per capita was approximately $20.000 €$, slightly below to the Spanish average $(22.413 €)$. The activity rate amounts to about $61 \%$ of the population ( $60 \%$ Spanish average), while the unemployment rate of the active population was $21,24 \%$ $18 \%$ for Spain - (INE, 20II). The relevance of micro-firms (less than 5 employees) and SMEs (up to 50 employees) is also notorious. In $2009,89,75 \%$ of regional firms had less than 5 employees, 9,46\% had between 6 and 49 , and $0,78 \%$ had more than 50 employees. Out of these, only 127 firms $(0,035 \%)$ were larger than 500 employees (INE, 20II).

\footnotetext{
${ }^{4}$ For Büyüközkan and Feyzioglu (2004:28) uncertainty is defined as the difference between the amount of information required to perform a particular task and the amount of information already possessed.
} 
The reasons to conduct our research in this region are manifold. First, it has some structural features not to be found in any other Spanish region. Its productive structure is primarily composed by family-owned micro-firms and SMEs in traditional manufacturing sectors (e.g. shoes, ceramics, furniture, textile, tiles, toys, etc.), none of which are considered as knowledge-intensive. Namely, it is a clear example of how innovation can be accomplished by adaptation in traditional low-tech sectors (Robertson et al., 2009). Second, it's most relevant sectors such as wood, tiles, ceramics, toy industry, footwear and textiles are grouped in industrial districts. In fact, the Valencian case is regarded as one of the first Spanish regions (together with the Basque Country) applying the concept of clusters in order to support their regional firms (Ahedo Santisteban, 2006). Third, innovative firms in the region mostly base their NPD processes on the acquisition of foreign machinery (Fernández de Lucio et al., 2000) and not that much on the development of R\&D activities, which conveys the low technological profile of the companies (Edwards-Schachter et al., 20II). Finally, despite all the above arguments, the region still ranks fourth among Spanish regions in terms of its innovative capacity (Zabala-Iturriagagoitia et al., 2007a, 2007b) after Catalonia, Madrid and Andalusia. Besides, these regions have already been studied in the literature (Bacaria et al., 200I; Real Heredia, 200I; Riba Vilanova and Leydesdorff, 200I; Albert and Plaza, 2003).

By focusing on a region with low absorptive capacity, where most of its economic activities are based on traditional low-tech sectors, but that nevertheless manages to introduce new innovations in the market, we want to check the degree of generality of Krishnan and Ulrich's (200l) contribution.

The target population consists of about 1.200 companies in different sectors catalogued as innovative by DIRNOVA $(1999)^{5}$ DIRNOVA follows the definition provided by the Community Innovation Survey (CIS) as to which firms are regarded as innovative. That is, those firms having introduced a new or significantly improved product (good or service) to the market or a new or significantly improved process are regarded as innovative (Eurostat, 2010). We consider that the inclusion of all firms (innovative and non-innovative) could introduce noise in the surveyed population. That is the reason why we focus on innovative firms, and not on all the population of firms in the region (innovative and non-innovative). Moreover, since we are interested in analyzing NPD processes, firms with product innovations were considered as the population that could best fit with our requirements.

The questionnaire was sent to all the firms in the DIRNOVA database in September 2004. Firms were requested to submit their answers not later than January 2005. The number of answers received was 136, which represents a response rate of $\mathrm{II}, 3 \%$. After data cleaning, 119 effective questionnaires were obtained. Due to the low-tech orientation of (most of) the companies we were interested in, a mail survey was preferred to other procedures such as e-mail or web-based questionnaires. Despite we agree on the fact that these alternative methods could facilitate and increase our response rate, we had to consider that most of the targeted companies did not count on any alternative ways to contact them (e.g. e-mail, telephone, website) rather than formal address.

\subsection{Questionnaire design}

The questionnaire was divided into two sections (see Table 2), listing the most common decisions identified by Krishnan and Ulrich (200I). These two sections had to be answered according to a 4 point Likert scale (Never = I, Occasionally $=2$, Often $=3$, Always $=4$ ).

The questionnaire was sent together with a brief letter, showing our gratitude for participating in the survey, followed by a detailed instruction on how to answer the formulated questions. The documentation was carefully prepared and submitted by post to the attention of the general manager of each company. One could argue the reasons for us to submit the questionnaires to the general manager of the company instead of sending them to the project manager. As we have said above, most Valencian firms are familiar micro-firm and SMEs. This implies that several roles are played by the same individuals in the company. Accordingly, it is hard to find a firm where a single person would play the role of project manager. On the contrary, if one aims to ensure the questionnaire being received by the person with decision-making authority and a wide view of the firm, then the general manager

${ }^{5}$ DIRNOVA - Directorio de Empresas Innovadoras de la ComunidadValenciana (Innovative Firm Database of the Valencian Region). 
necessarily needs to be reached. Each general manager was provided one questionnaire together with and envelope with our office address and the corresponding stamp, so they could send their answers back once they were filled in without further circumstances.

\subsection{Data processing and analysis}

The information gathered was complemented by additional data through SABI $(2006)^{6}$, a database that collects the financial situation of those Spanish firms whose turnover is higher than $600.000 €$ or have more than 10 employees. The new indicators collected for each firm in the sample were turnover (in Million $€$ ), export rate (\%), size (number of employees) and year of foundation, being the reference year 2006.

\begin{tabular}{|c|c|c|c|c|c|c|c|c|}
\hline & \multicolumn{3}{|c|}{ Year of establishment } & \multicolumn{4}{|c|}{ Size (number of employees) } & \multirow[b]{2}{*}{ TOTAL } \\
\hline & $\begin{array}{c}1893-1977 \\
(\mathrm{~N}=42)\end{array}$ & $\begin{array}{c}1978-1996 \\
(\mathrm{~N}=52)\end{array}$ & $\begin{array}{c}\text { Unknown } \\
(\mathrm{N}=25)\end{array}$ & $\begin{array}{c}<25 \\
(\mathrm{~N}=36) \\
\end{array}$ & $\begin{array}{l}26-49 \\
(\mathrm{~N}=29)\end{array}$ & $\begin{array}{c}\geq 50 \\
(\mathrm{~N}=20)\end{array}$ & $\begin{array}{c}\text { Unknown } \\
(\mathrm{N}=34)\end{array}$ & \\
\hline \multicolumn{9}{|c|}{ 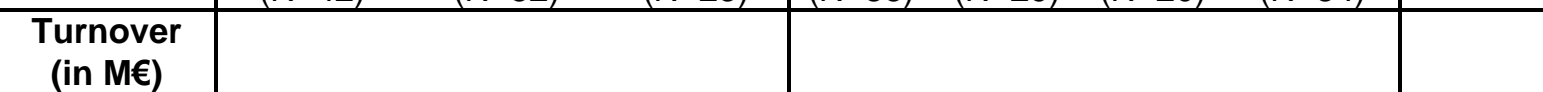 } \\
\hline$<1,5$ & 5 & 26 & 0 & 24 & 5 & 0 & 2 & 31 \\
\hline $1,5-9$ & 18 & 13 & 2 & 10 & 20 & 3 & 0 & 33 \\
\hline$\geq 9$ & 14 & 10 & 1 & 2 & 4 & 17 & 2 & 25 \\
\hline Unknown & 5 & 3 & 22 & 0 & 0 & 0 & 30 & 30 \\
\hline Total & & & & & & & & 119 \\
\hline \multicolumn{9}{|l|}{$\begin{array}{c}\begin{array}{c}\text { Export rate } \\
(\%)\end{array} \\
\text { (\%) }\end{array}$} \\
\hline$<25 \%$ & 18 & 17 & 1 & 12 & 13 & 9 & 2 & 36 \\
\hline$\geq 25 \%$ & 15 & 19 & 1 & 13 & 11 & 9 & 2 & 35 \\
\hline Unknown & 9 & 16 & 23 & 11 & 5 & 2 & 30 & 48 \\
\hline Total & & & & & & & & 119 \\
\hline
\end{tabular}

Table I.- General descriptive statistics of the firms in the sample / Source: own elaboration from SABI database (2006)

Table I describes some of the main features of the sampled firms. Despite generalization is not possible from our sample, we must declare that it also reflects to some extent certain characteristics of the regional economy. In fact, the process of growth that the Valencian economy has gone through since 1978 can be noticed. 42 of the 119 firms were established between 1893 (year of foundation of the oldest firm in the sample) and 1977. Nearly half (52 firms) were born between 1978 (year of the Spanish constitution) and 1996 (year of foundation of the youngest firm in the sample). The data regarding the size of the firms evidences the composition of Valencian companies. 36 out of the 119 firms (30,3\%) have less than 25 employees, 29 (24,4\%) between 26-49, and 20 companies
$(16,8 \%)$ occupy more than 50 employees ${ }^{7}$. Finally, most firms' turnover is lower than 9 Million $€^{8}$ while the export rate follows quite a uniform distribution. As one can observe, the distribution of the firms in the sample by size is more homogeneous than that of the entire population, which is totally biased towards firms with less than 5 employees. We considered that having a more homogeneous distribution in the sample may help us to provide better and more robust conclusions for the analysis, since the vast majority of companies employ less than 5 people. This is the reason why we aimed at gathering more data than that to be representative of the original distribution of companies between 26 and 49 employees and those larger than 50.

\footnotetext{
${ }^{6} \mathrm{SABI}$ - Sistema de Análisis de Balances Ibéricos (Iberian Balance Sheet Analytical System).

7 From these 20 companies, only 3 employ more than 250 employees.

${ }^{8}$ Only 4 firms have a turnover between 30 and 60 Million $€$, and only two of them achieve more than 90 Million $€$.
} 


\section{Results}

In order to clarify and make our results more structured, this section will be divided into two parts. The first subsection will describe the results of the questions identified by Krishnan and Ulrich (200l) among Valencian innovative firms. Therewith we aim to verify whether these questions can also be regarded as key within the NPD processes in this particular case. Then second, we will apply a factor analysis to illustrate if the groups of decisions identified by Krishnan and Ulrich according to their state-of-the-art review can be confirmed in our empirical sample.

\section{I. Illustrating the potential utility of Krishnan and Ulrich}

The first set of questions addressed by Krishnan and Ulrich are those related to the Product Development Decisions within a project. We have labelled these questions as $\mathrm{New}$ Product Development (NPD). In general terms, we can observe that the majority of firms consider most of the decisions with a high frequency. As regards the decisions listed under "concept development" (NPDI to NPD6), the firms in the sample declare they always ponder most of them. In fact, the core product concept (NPD2) seems to be the only question which is not contemplated with a high frequency. The "product design" subset (NPD7 to NPD9) shows similar conclusions, with the only particularity that $9,48 \%$ of the sampled firms show no concern about the configuration of the components and assembly precedence relations (NPD8). The "performance testing and validation" (NPDI0 and NPDII) shows some interesting results. $12 \%$ of the firms never consider these questions in their NPD processes. This clearly shows the low technology orientation of Valencian firms, who don't consider prototyping and testing activities to be related to the products they commercialize. Mostly, they base their innovation activities in the acquisition of machinery developed elsewhere (Fernández de Lucio et al., 2000). "Supply chain design" related issues (NPDI2 to NPDI6) are also discussed by most firms. However, a short reference regarding the configuration of the physical supply chain (NPDI4) is needed. Due to the small size of Valencian firms (see Table I), they seldom commercialize their products on their own. In contrast, they generally group themselves in clusters or cooperatives so as to gain more negotiation power or supply bigger enterprises not aiming at producing their goods but distributing them. This is the main reason for $13 \%$ of the firms no to show any concern regarding the configuration of their supply chain. Finally, the answers related to the group "production ramp-up and launch" (NPDI7 and NPDI8) show similar conclusions. Indeed, and due to the reasons illustrated above, $17 \%$ of the firms never consider their plans for market testing and launch.

The second group of questions recognized by Krishnan and Ulrich deals with the decisions made in setting up a development project. We have labelled this set of questions as Project Management (PM). The results obtained show that the firms in the sample do not consider these aspects to the extent they did with NPD questions. In fact, the percentage of firms that 'never' consider these topics is quite high. See the results for the questions PM6, PM7, PM8 and PMII, where the majority of the sampled firms never or only occasionally make these decisions. The commercialization issue addressed above applies as well for the question concerning which platforms will be shared across which products (PM4), a question that 10\% of the firms never consider at all. The "product development organization" subset (PM6 to PMII) is the one that more clearly illustrates the particularities of Valencian firms. Due to their small size, their low-tech orientation and especially their low absorptive capacity (Vega-Jurado et al., 2009) regional firms struggle to achieve marketing and organizational innovations. Their main efforts are oriented towards process innovation, which is mostly achieved by the acquisition of foreign machinery. This is one of the reasons why regional firms show no concern as to issues like the organizational structure (PM6), coordination among teams (PM7), monitoring and evaluation (PM8) or the type of development process to be employed (PMII). 


\begin{tabular}{|c|c|c|c|c|}
\hline \multirow{2}{*}{ Questionnaire items } & \multicolumn{4}{|c|}{$\%$ of firms } \\
\hline & Never & Occasionally & Often & Always \\
\hline \multicolumn{5}{|l|}{ Product Development Decisions within a Project } \\
\hline \multicolumn{5}{|l|}{ Concept Development } \\
\hline $\begin{array}{l}\text { NPD1.- What are the target values of the product attributes, including } \\
\text { price? }\end{array}$ & 7,02 & 13,16 & 34,21 & 45,61 \\
\hline NPD2.- What is the core product concept ${ }^{\perp}$ ? & 4,55 & 21,82 & 38,18 & 35,45 \\
\hline NPD3.- What is the product architecture ${ }^{<}$? & 7,89 & 21,93 & 28,95 & 41,23 \\
\hline NPD4.- What variants of the product will be offered? & 6,96 & 24,35 & 33,91 & 34,78 \\
\hline $\begin{array}{l}\text { NPD5.- Which components will be shared across which variants of the } \\
\text { product? }\end{array}$ & 6,03 & 23,28 & 30,17 & 40,52 \\
\hline $\begin{array}{l}\text { NPD6.- What will be the overall physical form and industrial design }{ }^{5} \text { of } \\
\text { the product? }\end{array}$ & 3,48 & 13,91 & 24,35 & 58,26 \\
\hline \multicolumn{5}{|l|}{ Product design } \\
\hline NPD7.- What are the values of the key design parameters ${ }^{4}$ ? & 4,31 & 16,38 & 38,79 & 40,52 \\
\hline $\begin{array}{l}\text { NPD 8.- What is the configuration of the components and assembly } \\
\text { precedence relations } 5^{5} \text { ? }\end{array}$ & 9,48 & 25,86 & 24,14 & 40,52 \\
\hline $\begin{array}{l}\text { NPD 9.- What is the detailed design of the components, including } \\
\text { material and process selection? }\end{array}$ & 6,90 & 17,24 & 21,55 & 54,31 \\
\hline \multicolumn{5}{|l|}{ Performance testing and validation } \\
\hline NPD10.- What is the prototyping plan? & 12,93 & 27,59 & 25,86 & 33,62 \\
\hline NPD11.- What technologies should be used for prototyping? & 12,07 & 30,17 & 26,72 & 31,03 \\
\hline \multicolumn{5}{|l|}{ Supply chain design } \\
\hline $\begin{array}{l}\text { NPD12.- Which components will be designed and which will be } \\
\text { selected? Who will design the components? }\end{array}$ & 8,77 & 19,30 & 36,84 & 35,09 \\
\hline NPD13.- Who will produce the components and assemble the product? & 8,77 & 20,18 & 28,95 & 42,11 \\
\hline $\begin{array}{l}\text { NPD14.- What is the configuration of the physical supply chain, including } \\
\text { the location of the decouple point? }\end{array}$ & 13,39 & 32,14 & 30,36 & 24,11 \\
\hline NPD15.- What type of process will be used to assemble the product? & 4,39 & 20,18 & 28,07 & 47,37 \\
\hline $\begin{array}{l}\text { NPD16.- Who will develop and supply process technology and } \\
\text { equipment? }\end{array}$ & 6,09 & 20,87 & 35,65 & 37,39 \\
\hline \multicolumn{5}{|l|}{ Production ramp-up and launch } \\
\hline NPD17.- What is the plan for market testing and launch? & 17,39 & 37,39 & 22,61 & 22,61 \\
\hline NPD 18.- What is the plan for production ramp-up? & 7,76 & 32,76 & 28,45 & 31,03 \\
\hline \multicolumn{5}{|l|}{ Decisions in Setting up a Development project } \\
\hline \multicolumn{5}{|l|}{ Product strategy and planning } \\
\hline $\begin{array}{l}\text { PM1.- What is the market and product strategy to maximize probability } \\
\text { of economic success? }\end{array}$ & 5,45 & 37,27 & 30,91 & 26,36 \\
\hline PM2.- What portfolio of product opportunities will be pursued? & 7,08 & 34,51 & 37,17 & 21,24 \\
\hline PM3.- What is the timing of product development projects? & 5,36 & 34,82 & 37,50 & 22,32 \\
\hline $\begin{array}{l}\text { PM4.- What, if any, assets (e.g. platforms) will be shared across which } \\
\text { products? }\end{array}$ & 10,71 & 32,14 & 34,82 & 22,32 \\
\hline PM5.- Which technologies will be employed in the product(s)? & 3,57 & 30,36 & 34,82 & 31,25 \\
\hline
\end{tabular}

Table 2.- Distribution of New Product Development decisions / Source: own elaboration

\footnotetext{
9 Product concept: frame or technological approach in which the product attributes are identified.

${ }^{10}$ Product architecture: product breakdown in which the technologies and components used in its assembly are identified.

"Industrial Design: structure or physical shape adopted by the product.

${ }^{12}$ Key parameters: product attributes whose function is essential for the correct operation of the product.

${ }^{13}$ Precedence relations: order in which the components constituting the architecture of the product have to be assembled.
} 


\begin{tabular}{|c|c|c|c|c|}
\hline \multicolumn{5}{|l|}{ Product development organization } \\
\hline PM6.- Will a functional, project or matrix organization be used? & 26,36 & 25,45 & 31,82 & 16,36 \\
\hline PM7.- How will the team be staffed? & 21,82 & 27,27 & 25,45 & 25,45 \\
\hline PM8.- How will project performance be measured? & 17,86 & 32,14 & 31,25 & 18,75 \\
\hline PM9.- What will be the physical arrangement and location of the team? & 19,82 & 25,23 & 25,23 & 29,73 \\
\hline $\begin{array}{l}\text { PM10.- What investments in infrastructure, tools and training will be } \\
\text { made? }\end{array}$ & 7,96 & 32,74 & 27,43 & 31,86 \\
\hline $\begin{array}{l}\text { PM11.- What type of development process will be employed (e.g. stage- } \\
\text { gate)? }\end{array}$ & 33,03 & 23,85 & 27,52 & 15,60 \\
\hline \multicolumn{5}{|l|}{ Project Management } \\
\hline PM12.- What is the relative priority of development objectives? & $\overline{9,17}$ & 26,61 & 34,86 & 29,36 \\
\hline $\begin{array}{l}\text { PM13.- What is the planned timing and sequence of development } \\
\text { activities? }\end{array}$ & 10,91 & 28,18 & 30,00 & 30,91 \\
\hline PM14.- What are the major project milestones and planned prototypes? & 10,00 & 30,91 & 38,18 & 20,91 \\
\hline $\begin{array}{l}\text { PM15.- What will be the communication mechanism among team } \\
\text { members? }\end{array}$ & 11,71 & 27,03 & 35,14 & 26,13 \\
\hline PM16.- How will the project be monitored and controlled? & 9,82 & 22,32 & 33,04 & 34,82 \\
\hline
\end{tabular}

Table 2.- Distribution of New Product Development decisions / Source: own elaboration

The previous description clearly illustrates how small firms in low- tech traditional sectors follow a less structured and less disciplined approach to NPD than their medium-sized and large counterparts. Furthermore, they possess limited resources and pursue a less defined company strategy, while their internal procedures are more vague. In addition small firms can be more flexible with less barriers for internal communication.

With these results in mind, we can conclude on the one hand that the questions identified by Krishnan and Ulrich's literature review are also made within the context of analysis of the Valencian Region. This may be regarded as a somehow expected result since their seminal contribution was made on over 200 previous studies. However, if we take into consideration that our sample mostly consists of traditional firms and micro and smallsized companies, with innovation mostly being driven by adaptation, then this provides a new piece of evidence as to the generality of their results, which was mostly based on studies targeting medium and high-tech manufacturing companies. We consider more attention should be paid to understanding innovation processes in traditional industries where the role of absorptive capacity as a driver of innovation becomes crucial.

On the other hand, what could not be expected beforehand is the fact that the results would confirm the characteristics of the regional economy. As illustrated in section 3.I, the Valencian setting is mostly dominated by micro and SMEs located in the end of the value chain in their respective sectors of activity. In other words, supplier dominated companies (Pavitt, 1984) with very low power of negotiation as compared to other big competitors. One could thus argue if having supplier dominated companies influences the type of decisions most frequently made by regional companies. In fact, "Concept Development" and "Product Design" related decisions are much common that those in the "Performance testing and validation" and "Production ramp-up and launch" stages. Since most companies belong to traditional sectors and are located in the end of the value chain, testing activities are not done by them, but developed by their supplier companies, which are much higher in the value chain. The same applies for the lack of decisions made in the marketing phases of the NPD process. This is a clear reflect of the low value added activities regional firms are engaged in. New evidence can also be observed regarding the organizational structures prevailing in the region. As we have argued, most companies are familiar firms, where most decision-making is taken on by the general manager, who is usually either the founder or the one that inherited the company from the original founder. That was our rationale to send the correspondence to the general manager instead of asking for the project manager in charge of new product developments. This is evidenced by the data gathered within the stage related to "Product development organization", which constitutes the step where the decisions pointed out by Krishnan and Ulrich are most frequently never taken into consideration. 
Summing up, studying the items found by Krishnan and Ulrich not only helps us to better comprehend how the NPD process is carried out within regional firms, but also to identify some of their structural characteristics, which points at some positive linkages between the operations management and innovation system research, which still remain unexplored.

\subsection{To what extent can Krishnan and Ulrich's taxo- nomy be generalized?}

The goal of this subsection is to explore if the taxonomy of groups of decisions identified by Krishnan and Ulrich is also quantitatively rooted. It may be argued that their categorization was only concluded for organizational con- venience, grouping decisions according to the similarities among them and the role they play in the NPD process. Is however this intended search for clarification aligned with quantitative methods aimed at grouping factors according to their degree of homogeneity?

With this factor analysis, we aim to confirm the validity of the Krishnan and Ulrich (200l) contribution on the one hand. On the other, we also want to verify if Krishnan and Ulrich's distribution of factors (groups of decisions) is valid in the Valencian case. In case the groups of decisions identified by them would be valid in general terms, the factor analysis would confirm their theoretical distribution. The analysis has been performed with STATA 10 and the principal component factor command.

\begin{tabular}{|c|c|c|c|c|c|}
\hline \multicolumn{6}{|c|}{ Total explained variance } \\
\hline \multirow{2}{*}{\multicolumn{2}{|c|}{ Factors }} & \multicolumn{4}{|c|}{ Eigenvalues } \\
\hline & & Total & \multicolumn{2}{|c|}{$\%$ of the variance } & $\%$ accumulated \\
\hline & & 6,96 & \multicolumn{2}{|c|}{38,69} & 38,69 \\
\hline & & 1,99 & \multicolumn{2}{|c|}{11,03} & 49,72 \\
\hline & & 1,60 & \multicolumn{2}{|c|}{8,91} & 58,63 \\
\hline & & 1,39 & \multicolumn{2}{|c|}{7,71} & 66,34 \\
\hline & \multicolumn{5}{|c|}{ Factors } \\
\hline & 1 & 2 & 3 & 4 & Uniqueness \\
\hline NPD1 & 0,8477 & 0,0094 & $-0,0505$ & 0,0134 & 0,3028 \\
\hline NPD2 & 0,8463 & 0,0063 & 0,0479 & $-0,0408$ & 0,2663 \\
\hline NPD3 & 0,5738 & 0,4234 & 0,0369 & $-0,0339$ & 0,3617 \\
\hline NPD4 & 0,0275 & 0,8172 & $-0,1703$ & 0,1890 & 0,3450 \\
\hline NPD5 & 0,0576 & 0,8334 & $-0,0536$ & $-0,0148$ & 0,3292 \\
\hline NPD6 & $-0,0466$ & 0,7017 & 0,0191 & 0,1977 & 0,4071 \\
\hline NPD7 & 0,2507 & 0,3032 & 0,3836 & 0,0184 & 0,4613 \\
\hline NPD8 & 0,0020 & 0,5973 & 0,3186 & $-0,2561$ & 0,4103 \\
\hline NPD9 & $-0,0380$ & 0,3529 & 0,5015 & $-0,0761$ & 0,4974 \\
\hline NPD10 & 0,3488 & $-0,0309$ & $-0,0351$ & 0,6820 & 0,3150 \\
\hline NPD11 & 0,3256 & $-0,0459$ & $-0,0409$ & 0,7445 & 0,2496 \\
\hline NPD12 & $-0,1058$ & 0,0508 & 0,8441 & 0,0257 & 0,2894 \\
\hline NPD13 & $-0,0144$ & $-0,0266$ & 0,8510 & 0,0259 & 0,2922 \\
\hline NPD14 & 0,1861 & $-0,2181$ & 0,7319 & 0,2113 & 0,3064 \\
\hline NPD15 & $-0,0921$ & 0,1050 & 0,8107 & 0,0513 & 0,2717 \\
\hline NPD16 & 0,2468 & $-0,1526$ & 0,7268 & $-0,0171$ & 0,3844 \\
\hline NPD17 & $-0,1646$ & 0,0891 & 0,0610 & 0,8270 & 0,2967 \\
\hline NPD18 & $-0,2333$ & 0,1346 & 0,1733 & 0,7839 & 0,2718 \\
\hline
\end{tabular}

Table 3.- Rotated factor matrix for NPD questions/ Source: own elaboration 
The statistical distribution of the 18 questions labelled as new product development decisions (NPD) can be grouped in separated factors, following the patterns of four main underlying dimensions (Table 3 ). In the top of the table we see the four factors and their corresponding eigenvalues. The first peculiarity is the strong impact of the first factor. Its eigenvalue is outstandingly high, especially when compared with the others, which range between I,4 and 2. The first factor is responsible for nearly $40 \%$ of the variation in the sample, while the other three factors account for a share of $7,7-11 \%$ of the variation. The other potential factors are not listed since their eigenvalue is smaller than I. Therefore, they are not considered as separate factors with major impact.

The second part of the table shows the relevance of each question for the four underlying factors, after the matrix pattern was rotated for a clearer classification. The highest factor loading for each question, and therefore the group belonging, is marked in bold. The factor loadings make very clear that the first three questions (NPDI-NPD3) belong to factor I, which we have interpreted as 'Core product specifications'. Further we find questions NPD4 to NPD6 and NPD8 in factor 2, labelled as 'Product variants and their assembly'. Questions NPD7, NPD9 and NPDI2 to NPDI6 belong to factor 3, 'Product value-chain (design, production and commercialization)'. In the fourth factor, which we summarized under the umbrella term of 'Product performance testing', we find four questions (NPDI0-II and NPD 17-18) ${ }^{14}$. This is aligned with the findings of the previous subsection. The 'Core product specifications' is the factor explaining most of the variance, and as Table 2 illustrated the decisions regarding concept development and product design (in Krishnan and Ulrich's words) were the most common to be made by regional firms. Likewise, the other three factors, which are related to the value chain and the testing of the products/services, are not that relevant for the sampled firms.

The last column contains the value for the uniqueness for every question. This represents the share of each question which can't be explained by the information provided by the other questions. Remarkable is that the values for the uniqueness are very similar and smaller than $50 \%$ in all cases. This is a sign that the questions share a huge load of information with each other. Subsequently a reduction of questions by factor analysis according to the underlying dimensions can be considered as a valid procedure.

Table 4, displays the questions identified by Krishnan and Ulrich about Project Management (PM). After applying the factor analysis, the questions are divided into two underlying dimensions. The first one has a very strong impact with a eigenvalue of 8,1 , what makes the factor responsible for over $50 \%$ of the variation in the sample. The impact of the second factor is smaller but still valid since its eigenvalue is about I,4. Due to that, the factor is responsible for about $9 \%$ of the variation in the sample. Together both factors can explain about $60 \%$ of the variation. The questions PMI-PM7 and PM9 belong to the first factor, termed as 'Product strategy, planning and firm internal organization'. Then, in the second factor we find questions PM8 and PMI0-PMI6, regarded as 'Project management and monitoring'. This also relates to the internal organizational structures of Valencian firms, which as we have pointed out along the paper are mostly familiar micro-firms in traditional sectors, where hierarchy is still preeminent. The uniqueness values are in a range of $20-52 \%$, which is again a sign that substantial parts of the information provided by each question are also implied in other questions. A reduction of the battery of questions via factor analysis is confirmed as a valid instrument. 14 When referring to "products" in the labels of the previous factors, we also mean the services developed. The word "services" has not
been included for a matter of simplicity in the labeling. 


\begin{tabular}{|c|c|c|c|}
\hline \multicolumn{4}{|c|}{ Total explained variance } \\
\hline \multirow{2}{*}{ Factors } & \multicolumn{3}{|c|}{ Eigenvalues } \\
\hline & Total & $\%$ of the variance & $\%$ accumulated \\
\hline 1 & 8,114 & 50,713 & 50,713 \\
\hline 2 & 1,435 & 8,967 & 59,681 \\
\hline & \multicolumn{3}{|c|}{ Factors } \\
\hline & 1 & 2 & Uniqueness \\
\hline PM1 & 0,6401 & 0,0829 & 0,5171 \\
\hline PM2 & 0,9594 & $-0,1187$ & 0,2078 \\
\hline PM3 & 0,8883 & $-0,0608$ & 0,2747 \\
\hline PM4 & 0,8220 & $-0,0564$ & 0,3790 \\
\hline PM5 & 0,5059 & 0,1571 & 0,6201 \\
\hline PM6 & 0,5162 & 0,3107 & 0,4367 \\
\hline PM7 & 0,4948 & 0,3982 & 0,3505 \\
\hline PM8 & 0,1084 & 0,7506 & 0,3232 \\
\hline PM9 & 0,4878 & 0,3389 & 0,4407 \\
\hline PM10 & $-0,1051$ & 0,7845 & 0,4765 \\
\hline PM11 & 0,0870 & 0,7110 & 0,4097 \\
\hline PM 12 & $-0,1366$ & 0,8427 & 0,4150 \\
\hline PM13 & 0,0989 & 0,7302 & 0,3668 \\
\hline PM14 & 0,2094 & 0,5816 & 0,4658 \\
\hline PM15 & 0,0804 & 0,6582 & 0,4942 \\
\hline PM16 & $-0,0953$ & 0,9088 & 0,2733 \\
\hline
\end{tabular}

Main rotated components. Rotation method, Promax. Group belonging marked in bold.

Table 4.- Rotated factor matrix for PM questions/ Source: own elaboration

As a result, the statistical division in underlying factors shows a different distribution to Krishnan and Ulrich's theoretical approach. These two different distributions are compared and interpreted with the help of Table 5 and Table 6. 


\begin{tabular}{|c|c|}
\hline Krishnan and Ulrich (2001) & Factor analysis results \\
\hline Concept development & Core product specifications \\
\hline \multirow{3}{*}{$\begin{array}{l}\text { NPD1.- What are the target values of the product attributes, including price? } \\
\text { NPD2.- What is the core product concept? } \\
\text { NPD3.- What is the product architecture? } \\
\text { NPD4.- What variants of the product will be offered? } \\
\text { NPD5.- Which components will be shared across which variants of the product? } \\
\text { NPD6.- What will be the overall physical form and industrial design of the product? }\end{array}$} & $\begin{array}{l}\text { NPD1.- What are the target values of the product attributes, including price? } \\
\text { NPD2.- What is the core product concept? } \\
\text { NPD3.- What is the product architecture? }\end{array}$ \\
\hline & Product variants and their assembly \\
\hline & \multirow{3}{*}{$\begin{array}{l}\text { NPD4.- What variants of the product will be offered? } \\
\text { NPD5.- Which components will be shared across which variants of the product? } \\
\text { NPD6.- What will be the overall physical form and industrial design of the product? } \\
\text { NPD8.- What is the configuration of the components and assembly precedence } \\
\text { relations? }\end{array}$} \\
\hline Product design & \\
\hline \multirow{3}{*}{$\begin{array}{l}\text { NPD7.- What are the values of the key design parameters? } \\
\text { NPD8.- What is the configuration of the components and assembly precedence } \\
\text { relations? } \\
\text { NPD9.- What is the detailed design of the components, including material and } \\
\text { process } \\
\text { selection? }\end{array}$} & \\
\hline & Product value-chain (design, production and commercialization) \\
\hline & \multirow{6}{*}{$\begin{array}{l}\text { NPD7.- What are the values of the key design parameters? } \\
\text { NPD9.- What is the detailed design of the components, including material and } \\
\text { process } \\
\text { selection? } \\
\text { NPD12.- Which components will be designed and which will be selected? Who will } \\
\text { design } \\
\text { the components? } \\
\text { NPD13.- Who will produce the components and assemble the product? } \\
\text { NPD14.- What is the configuration of the physical supply chain, including the } \\
\text { location of } \\
\text { the decouple point? } \\
\text { NPD15.- What type of process will be used to assemble the product? } \\
\text { NPD16.- Who will develop and supply process technology and equipment? }\end{array}$} \\
\hline Performance testing and validation & \\
\hline $\begin{array}{l}\text { NPD10.- What is the prototyping plan? } \\
\text { NPD11.- What technologies should be used for prototyping? }\end{array}$ & \\
\hline Supply chain design & \\
\hline \multirow{4}{*}{$\begin{array}{l}\text { NPD12.- Which components will be designed and which will be selected? Who will } \\
\text { design } \\
\text { the components? } \\
\text { NPD13.- Who will produce the components and assemble the product? } \\
\text { NPD14.- What is the configuration of the physical supply chain, including the } \\
\text { location of } \\
\text { the decouple point? } \\
\text { NPD15.- What type of process will be used to assemble the product? } \\
\text { NPD16.- Who will develop and supply process technology and equipment? }\end{array}$} & \\
\hline & \\
\hline & Product performance testing \\
\hline & $\begin{array}{l}\text { NPD10.- What is the prototyping plan? } \\
\text { NPD11.- What technologies should be used for prototyping? } \\
\text { NPD17.- What is the plan for market testing and launch? }\end{array}$ \\
\hline Production ramp-up and launch & NPD 18.- What is the plan for production ramp-up? \\
\hline $\begin{array}{l}\text { NPD17.- What is the plan for market testing and launch? } \\
\text { NPD 18.- What is the plan for production ramp-up? }\end{array}$ & \\
\hline
\end{tabular}

Table 5.- Comparison of factor distribution among the Product Development Decisions within a Project 
Regarding the Product Development Decisions within a Project (Table 5), one of the major differences between both distributions is the number of underlying factors for the 18 questions investigated. Krishnan and Ulrich divided their battery of questions in five sections, while the factor analysis suggests a distribution in only four factors. In addition, in Krishnan and Ulrich's contribution all factors are given the same significance (relative weight), without evidencing if and why any of their groups of decisions are more or less relevant, as our case exemplifies. We agree the list of decisions they proposed could be a good illustration of internal firm management practices in NPD processes ${ }^{15}$, but we disagree it can be extrapolated to firms in every sector in every location. Management practices differ across sectors and so do geography and path dependence. In other words, the particularities of the local environment and the firms are not taken into consideration by them. Accordingly, we consider their taxonomy could be adapted to different sectors, defining which decisions are more relevant for which sectors. Our research makes a first step into that categorization.

Nevertheless, the two distributions also share some common patterns. The first factor identified by Krishnan and Ulrich contains six questions (NPDI-NPD6), which the factor analysis separated in two different clusters. While they consider the "development of the concept" to be a single sub process including aspects like the target values of the good, the product architecture, the different variants of the good, etc., our analysis divides this stage into two phases: the first one related to the 'core product specifications', and the second regarding the potential variants of that core product.

The questions NPD7 and NPD9 seem to constitute a set as well. In Krishnan and Ulrich's version, these build their second factor ("Product design") together with question NPD8. According to the factor analysis though, the latter question belongs together with questions NPD4-NPD6 within the 'Product variants and their assembly' factor. Following, Krishnan and Ulrich suggest two separate factors with two questions each ("Performance testing and validation" - NPD 10 and NPD II - and "Production ramp-up and launch" - NPD 17 and NPD 18). These four questions build together one common factor related to the 'Product performance testing' following the statistical distribution. Finally, the remaining questions NPDI2-NPDI6 compose the last factor in Krishnan and Ulrich's theoretical division ("Supply chain design"). According to the factor analysis, these five questions are matched with NPD7 and NPD9 with the factor related to the product value-chain, where the aspects related to the design, production and commercialization of the good are included.

As to the Decisions in Setting up a Development project (Table 6) we find a different distribution in their theoretical and our empirical divisions. On the theory side, Krishnan and Ulrich suggest three factors for the 16 questions, while the factor analysis results in only two different clusters. Krishnan and Ulrich distinguished questions PMI-PM5 in one factor ("Product strategy and planning"), PM6-PMII in the second ("Product development organization"), and the remaining PMI2-PMI6 in the third and last factor ("Project Management"). This does clearly illustrate their taxonomy not being adapted to traditional sectors as argued before. In their view, the decisions in and during the setting up of a new product development project are made by different entities, such as those in charge of the general strategy and planning, those responsible for the organization of the product development and those accountable for the project management. However, in SMEs operating in traditional sectors decision-making processes are mostly a business of the general manager of the company, who decides what and how to do. In addition, as previously stressed, small firms in low-tech traditional sectors follow a less structured and less defined approach to new product development. Our empirical findings show how the most relevant factor is the one dealing with the 'Product strategy, planning and firm internal organization', which includes most of the decisions identified by Krishnan and Ulrich in their first two factors.

As a matter of fact, the factor analysis grouped questions PMI-PM7 together with PM9 in one factor and PMI0-PMI6 alongside PM8 in the other. It can be observed that the first five (PMI-PM5) and last five questions (PMI2-PMI6) are bonded each other in both distributions. However,

\footnotetext{
15 However, as it will be discussed in the concluding section, we believe their questions only refer to decision-making processes which are internal to the firm, excluding those decisions related to the external environment, so their view of the management of the NPD process is somehow biased.
} 
as just discussed, the other six questions (PM6-PMII) are distributed in a different way between the theory and the empirics found in our sample. We consider that while the distribution of Krishnan and Ulrich may be more applicable to large and medium-sized corporations involved in medium and high-tech industries, it does not relate to the particularities of traditional sectors.

From the above analysis, we can then conclude that the theoretical distribution proposed by Krishnan and Ulrich is confirmed as relevant in this empirical study. Some sets of questions showing very similar patterns could be identified in both cases, what partially verifies their theoretical findings. On the other hand, the differences are too prominent so as to merely focus on the theoretical side, neglecting the evidence to be found in the empirics. 


\begin{tabular}{|c|c|}
\hline Krishnan and Ulrich (2001) & Factor analysis results \\
\hline Product strategy and planning & Product strategy, planning and firm internal organization \\
\hline $\begin{array}{l}\text { PM1.- What is the market and product strategy to maximize probability of economic } \\
\text { success? } \\
\text { PM2.- What portfolio of product opportunities will be pursued? } \\
\text { PM3.- What is the timing of product development projects? } \\
\text { PM4.- What, if any, assets (e.g. platforms) will be shared across which products? } \\
\text { PM5.- Which technologies will be employed in the product(s)? }\end{array}$ & \multirow{3}{*}{$\begin{array}{l}\text { PM1.- What is the market and product strategy to maximize probability of economic } \\
\text { success? } \\
\text { PM2.- What portfolio of product opportunities will be pursued? } \\
\text { PM3.- What is the timing of product development projects? } \\
\text { PM4.- What, if any, assets (e.g. platforms) will be shared across which products? } \\
\text { PM5.- Which technologies will be employed in the product(s)? } \\
\text { PM6.- Will a functional, project or matrix organization be used? } \\
\text { PM7.- How will the team be staffed? } \\
\text { PM9.- What will be the physical arrangement and location of the team? }\end{array}$} \\
\hline Product development organization & \\
\hline $\begin{array}{l}\text { PM6.- Will a functional, project or matrix organization be used? } \\
\text { PM7.- How will the team be staffed? }\end{array}$ & \\
\hline PM8.- How will project performance be measured? & \multirow{3}{*}{\begin{tabular}{|l} 
Project management and monitoring \\
PM8.- How will project performance be measured? \\
PM10.- What investments in infrastructure, tools and training will be made? \\
PM11.- What type of development process will be employed (e.g. stage-gate)? \\
PM12.- What is the relative priority of development objectives? \\
PM13.- What is the planned timing and sequence of development activities?
\end{tabular}} \\
\hline $\begin{array}{l}\text { PM9.- What will be the physical arrangement and location of the team? } \\
\text { PM10.- What investments in infrastructure, tools and training will be made? } \\
\text { PM11.- What type of development process will be employed (e.g. stage-gate)? }\end{array}$ & \\
\hline Project Management & \\
\hline $\begin{array}{l}\text { PM12.- What is the relative priority of development objectives? } \\
\text { PM13.- What is the planned timing and sequence of development activities? } \\
\text { PM14.- What are the major project milestones and planned prototypes? }\end{array}$ & $\begin{array}{l}\text { PM 14.- What are the major project milestones and planned prototypes? } \\
\text { PM 15.- What will be the communication mechanism among team members? } \\
\text { PM16.- How will the project be monitored and controlled? }\end{array}$ \\
\hline $\begin{array}{l}\text { PM15.- What will be the communication mechanism among team members? } \\
\text { PM16.- How will the project be monitored and controlled? }\end{array}$ & \\
\hline
\end{tabular}

Table 6.- Comparison of factor distribution among the Decisions in Setting up a Development project/ Source: own elaboration 


\section{5.- Conclusions and discussion}

Innovation is a complex and multidisciplinary field where NPD processes are considered as a central component. The literature shows that decisions made during the NPD process directly influence the final output (innovation) and the activities constituting the NPD process itself.

With this research we aim to link the theoretical approach and empirical evidence in the context of NPD and product innovation management, offering an instrument to gain insights about the innovation processes not only to researchers in the field but also to managers in innovative companies.

We have focused upon the contribution of Krishnan and Ulrich (200I), who identified the most common decisions made in each phase of the NPD process. Our opinion is that most decisions they listed are adequate for medium and large enterprises involved in medium and high-tech manufacturing sectors. By focusing in a region with low absorptive capacity, low R\&D orientation, industries positioned in low-technology sectors, family oriented micro-firm and SMEs, and where innovation is mostly done by adaptation we aim to examine the degree to which the decisions they registered are indeed generalizable. The study has been carried out in a sample of 119 innovative companies in the Valencian Region (Spain).

The added value of our contribution can be attributed to the fact that: (a) the work contributes to the empirical testing of a conceptual framework which identifies an extensive list of the most common decisions made in each phase of the NPD process, and (b) the empirical exercise undertaken targets small enterprises in traditional sectors located in a specific region, while most decisions identified by Krishnan and Ulrich are relevant for medium and large firms active in medium and high-tech industries in manufacturing.

As a summary, it can be confirmed that the decisions identified by Krishnan and Ulrich's literature review, correspond to those made within the context of analysis of the Valencian Region. This might have been expected, but if we bear in mind that our sample mostly consists of traditional firms, where innovation is mostly driven by adaptation, this provides a new piece of evidence as to the generality of their results. However, their theoretical contribution can only be partially verified. We have found enough evidence for substantial differences between their theoretical approach and our empirical study, so the validation of their taxonomy should not be overestimated. Our results also validate the structural characteristics of the firms in the Valencian innovation system. The Valencian setting is characterized by supplier dominated companies, micro-firm and SMEs in the end of the value chain in their respective sectors of activity. This implies that regional firms are more exposed to made decisions over aspects like "Concept Development" and "Product Design", rather than deciding on "testing and validation" or "Production ramp-up and launch" issues. Evidence could also be raised as to the prevailing organizational structures in the region. Most companies are familiar micro-firms where hierarchy is still present, so decisions are made by the general manager and not by different units, each playing a particular role during the NPD process, as their taxonomy would suggest.

One of our strongest points of disagreement with regard to Krishnan and Ulrich's taxonomy is the fact that in their categorization all factors are given equal relative weight. In other words, they do not consider certain groups of decisions could be more or less relevant to a particular set of firms or sectors, as our case exemplifies. We agree their list of most common decisions could be a good illustration of internal firm management practices in NPD processes. However, we do not believe it can be extrapolated to firms in every sector in every location. We consider their taxonomy could thus be adapted to different sectors, defining which decisions are more relevant for which sectors.

Be that as it may, our major disagreement lays in their questions only referring to decision-making processes which are internal to the firm, excluding those related to the external environment. Chesbrough (2003) introduced the concept of open innovation to exemplify that external knowledge sources also contribute to firms' innovation performance. As the extensive literature on the subject reflects, one of the key features of innovation is that it is a cooperative process. Accordingly, the absence of decisions related to the external environment of the company seems quite notorious to us. External sources of knowledge influence the management of innovation activities, so firms need to make decisions about such external factors as cooperation agreements with local universities or R\&D 
institutes, the decisions of suppliers and/or customers, the need of external technical assistance, etc. (Spithoven et al., 2010). However, this type of external-to-the-firm decisions are not contemplated by Krishnan and Ulrich, what in our understanding constitutes an important matter for further consideration.

We also consider more attention should be given to understanding innovation processes in traditional sectors where the role of absorptive capacity as a driver of innovation becomes crucial (Robertson et al., 2009). This paper sheds some light on the above aspects, despite only one region with these characteristics has been studied, what constitutes the major limitation of this study. Therefore, the possibility of generalizing our findings implies also a need to address territorial differences by conducting this or similar surveys in other regions in order to control for geographical particularities. This would increase the empirical evidence which could strengthen the theoretical contribution of Krishnan and Ulrich.

\section{About the Author}

Jon Mikel Zabala-Iturriagagoitia is Assistant Professor at CIRCLE on innovation policy analysis. Engineer in industrial organization from the University of Mondragon (2002), he holds a European Ph.D. in Engineering and Innovation Projects from the Polytechnic University of Valencia (2008). During his PhD process, Jon Mikel was member of the Institute of Innovation and Knowledge Management (INGENIO). From September to December 2006 he was visiting researcher at the Technical Research Centre of Finland (VTT) in Espoo. Between 2009 and 2011 he developed his post-doctoral endeavor at CIRCLE. He has a long experience as a lecturer in modules about R\&D and innovation indicators, project management, and technology and innovation management. He cooperates with several European and Latin American universities in courses regarding the management of innovation.

His research focuses on the following streams: Analysis of innovation systems, science and technology policies and evaluation, innovation support policies and innovation management tools.

\section{Acknowledgements}

The author is thankful to Monica Garcia Melon and Rocio Poveda Bautista for their assistance during the conduction of the survey and to Tina Hannemann for the statistical support.

\section{References}

AHEDO SANTISTEBAN, M. (2006). Business Systems and Cluster Policies in the Basque Country and Catalonia (1990-2004). European Urban and Regional Studies, 13(I), 25-39.

ALBERT, A., Plaza, L.M. (2003). The Transfer of Knowledge from the Spanish Public R\&D System to the Productive Sectors in the Field of Biotechnology. Scientometrics, 59(I), 3-14.

ALCAIDE-MARZAL, J., Tortajada-Esparza, E. (2007). Innovation assessment in traditional industries. A proposal of aestheticinnovationindicators.Scientometrics, 72(I),33-57.

AROSA, B., Iturralde, T., Maseda, A. (2010). Ownership structure and firm performance in non-listed firms: Evidence from Spain. Journal of Family Business Strategy, $\mathrm{I}(2), 88-96$.

BACARIA, J., Borrás, S., Fernández-Ribas, A. (200I). El sistema de innovación regional en Cataluña. In: Olazarán, M., Gómez Uranga, M. (Eds.), Sistemas Regionales de Innovación. Servicio Editorial de la Universidad del País Vasco, Bilbao. pp. 22I-249.

BUIJS, J. (2008). Action planning for new product development projects. Creativity and Innovation Management, 17(4), 319-333.

BÜYÜKÖZKAN, G., Feyzioglu, O. (2004). A fuzzy-logicbased decision-making approach for new product Development. International Journal of Production Economics, $90,27-45$.

CHESBROUGH, H.W. (2003). Open Innovation. The New Imperative for Creating and Profiting from Technology. Harvard Business School Press, Boston. 
COOPER, R.G. (1983). The Impact of New Product Strategies. Industrial Marketing Management, 12, 243-256.

COOPER, R.G. (1988). Predevelopment activities determine new product success. Industrial Marketing Management, 17(3), 237-247.

COOPER, R.G., Kleinschmidt, E.J. (1987). New Products: What Separates Winners from Losers? Journal of Product Innovation Management, 4, 169-184.

DIRNOVA (1999). Directorio de Empresas Innovadoras de la Comunidad Valenciana, IMPIVA, Valencia, ISBN 84482-2098-6, CD rom.

EDWARDS-SCHACHTER, M., Castro-Martínez, E., Fernández-de-Lucio, I. (20II). International Co-operation between Firms on Innovation and R\&D: Empirical Evidence from Argentina and Spain. Journal of Technology Management \& Innovation, 6(3), 126-I47.

EMMANUELIDES, P.A. (1993). Towards an integrative framework of performance in product development projects. Journal of Engineering and Technology Management, I0(4), 363-392.

EUROSTAT (2010). http://epp.eurostat.ec.europa.eu/cache/ ITY_SDDS/en/inn_cis5_sml.htm. Accessed August 2011.

FERNÁNDEZ DE LUCIO, I., Gutiérrez Gracia, A., Jiménez Sáez, F., Azagra Caro, J. (2000). El Sistema Valenciano de Innovación en el inicio del siglo XXI. Revista Valenciana d'Estudis Autonòmics, 30, 7-64.

GARAVELLI, A.C., Gorgoglione, M., Scozzi, B. (1999). Fuzzy logic to improve the robustness of decision support systems under uncertainty. Computers and Industrial Engineering, 37, 477-480.

GUIMARÃES MARUJO, L. (2009). Rework Impacts Evaluation through System Dynamics Approach in Overlapped Product Development Schedule. Journal of Technology Management \& Innovation, 4(2), 90-10I.

HANSEN, C.T. (200I). Verification of a new model of decision-making in design. Proceedings of I3th International Conference on Engineering Design (ICED 0I). Professional Engineering Publications, London. Pp. I0I-I08.
HAQUE, B., Pawar, K.S., Barson, R.J. (2000). Analysing organisational issues in concurrent new product development. International Journal of Production Economics, 67(2), 169-182.

HARMANCIOGLU, N., McNally, R.C., Calantone, R.J., Durmusogl, S.S. (2007). Your new product development (NPD) is only as good as your process: an exploratory analysis of new NPD process design and implementation. R\&D Management, 37(5), 399-424.

HART, S.J., Baker, M.J. (1994). The Multiple Convergent Processing Model of New Product Development. International Marketing Review, II(I), 77-92.

HAVERILA, M. (20I0). The Marketplace Variables in Successful and Unsuccessful NPD Projects in Technology Intensive Companies. Journal of Technology Management \& Innovation, 5(4), 121-136.

HIPP, C., Grupp, H. (2005). Innovation in the service sector: The demand for service-specific innovation measurement concepts and typologies. Research Policy, 34(4), $517-535$.

INE (20II). National Statistics Institute of Spain. http:// www.ine.es, Accessed August 2011.

KENGPOL, A., O'Brien, C. (200I) The development of a decision support tool for the selection of advanced technology to achieve rapid product development. International Journal of Production Economics, 69, 177-191.

KRISHNAN, V. (1998). Modeling ordered decision making in product development. European Journal of Operational Research, III, 35I-368.

KRISHNAN, V., Ulrich, K.T. (200I) Product development Decisions: A review of the literature. Management Science, $47(I)$, I-2I.

LEDWITH, A., O'Dwyer, M. (2009). Market Orientation, NPD Performance, and Organizational Performance in Small Firms. Journal of Product Innovation Management, 26(6), 652-661.

MAHAJAN, V., Wind, J. (1992). New product models: Practice, shortcomings and desired improvements. Journal of Product Innovation Management, 9(2), 128-139. 
MATHESON, D., Matheson, J. (1998). The Smart Organization Creating Value Through Strategic R\&D. Harvard Business School Press, Boston.

MC.CARTHY, I.P., Tsinopoulos, C., Allen, P., RoseAnderssen, C. (2006). New Product Development as a Complex Adaptive System of Decisions. Journal of Product Innovation Management, 23(5), 437-456.

MOLERO, J., Garcia, A. (2008). The innovative activity of foreign subsidiaries in the Spanish Innovation System: An evaluation of their impact from a sectoral taxonomy approach. Technovation, 28(II), 739-757.

MOULAERT, F., Martinelli, F., González, S., Swyngedouw, E. (2007) Social Innovation and Governance in European Cities: Urban Development Between Path Dependency and Radical Innovation. European Urban and Regional Studies, 14(3), 195-209.

OECD (2005). OECD Proposed Guidelines for Collecting and Interpreting Technological Innovation Data. Paris. Oslo Manual.

PAVITT, K. (1984). Sectoral patterns of technical change: towards a taxonomy and a theory. Research Policy, 13, 343-373.

POOLTON, J., Barclay, I. (1998). New Product Development: From Past Research to Future Applications. Industrial Marketing Management, 27(3), I97-2I2.

REAL HEREDIA, B. (200I). El sistema regional de innovación en Andalucía: estructura y autonomía. In: Olazarán, M., Gómez Uranga, M. (Eds.), Sistemas Regionales de Innovación. Servicio Editorial de la Universidad del País Vasco, Bilbao. pp. 299-325.

RIBA VILANOVA, M., Leydesdorff, L. (200I). Why Catalonia Cannot be Considered as a Regional Innovation System. Scientometrics, 50(2), 215-40.

ROBERTSON, P., Smith, K., von Tunzelmann, N. (2009). Innovation in low- and medium-technology industries. Research Policy, 38(3), 44I-446.

SABI (2006). Sistema de Análisis de Balances Ibéricos.
SCHMIDT, J.B., Sarangee, K.R., Montoya, M.M. (2009) Exploring New Product Development Project Review Practices. Journal of Product Innovation Management, 26(5), 520-535.

SCHUMPETER, J.A. (1934). The Theory of Economic Development: An Inquiry into Profits, Capital, Credit, Interest and the Business Cycle. Harvard University Press, Cambridge.

SHEIKH, S., Pecher, I., Steiber, N., Heckl, E. (2002). Support services for Micro, Small and Sole Proprietor's Businesses. Vienna: Austrian Institute for Small Business Research (IfGH). Commissioned by: Enterprise Directorate-General, European Commission.

SPITHOVEN, A., Clarysse, B., Knockaert, M. (2010). Building absorptive capacity to organise inbound open innovation in traditional industries. Technovation, 30, 130-141.

SRINIVAS, V., Shekar, B. (1997). Strategic decision-making processes: network-based representation and stochastic simulation. Decision Support Systems, 2I, 99-II0.

TSINOPOULOS, C., McCarthy, I. (2002). New product development as a complex system of decisions. IEEE International Engineering Management Conference, 2, 76I-765.

TUOMINEN, M., Piippo, P., Ichimura, T., Matsumoto, Y. (1999). An analysis of innovation management systems' characteristics. International Journal of Production Economics, 60-6I, 135-143.

URBAN, G.L., Hauser, J.R. (1993). Design and Marketing of New Products. Prentice-Hall Inc., Englewood Cliffs.

VEGA-JURADO, J.M., Gutiérrez-Gracia, A., Fernándezde-Lucio, I. (2009). La Relación entre las Estrategias de Innovación: Coexistencia o Complementariedad. Journal of Technology Management \& Innovation, 4(3), 74-88.

ZABALA-ITURRIAGAGOITIA, J.M., Jiménez-Sáez, F., Castro-Martínez, E., Gutiérrez-Gracia, A. (2007a). What indicators do (or do not) tell us about Regional Innovation Systems. Scientometrics, 70(I), 85-106.

ZABALA-ITURRIAGAGOITIA, J.M., Gutiérrez-Gracia, A., Jiménez-Sáez, F. (2007b). Benchmarking Innovation in the Valencian Community. European Urban and Regional Studies, 15(3), 249-263. 
J. Technol. Manag. Innov. 20I2, Volume 7, Issue I 